\title{
The EMS Website
}

Vicente Muñoz (Universidad Complutense de Madrid, Spain) and Armen Sergeev (Steklov Mathematical Institute, Moscow, Russia)

The European Mathematical Society (EMS) has three faces open to the general public, namely: the Newsletter, Social Media (Twitter, Facebook and Google) and the official webpage of the EMS: www.euro-math-soc.eu.

The website, in its current form, was launched in 2014 by former EMS Vice-President Martin Raussen and developed by Robert Carr, and it was announced in the Newsletter of the EMS, No. 94, December 2014, pp. 6-7. It is based on the content management system Drupal 7, which is currently good enough in terms of convenience and security but should be upgraded in the future to a more advanced and better designed version.

The website contains plenty of material serving as a store of information, presented in an accessible and reliable way. You start with the main page, where the most recent news appears in a nice layout, including a link to the current issue of the Newsletter. At the top of the page, you will find several clickable labels: News, Inside EMS, Membership, Jobs, Services, Scientific Activities, Publishing House and Travel Grants. Each of them has a collection of sub-labels referring to different pages of the site. For the convenience of the readers of the Newsletter, we will give a short overview of the most useful features.

Entering "News", you will find a list of various current events, such as announcements of mathematical prizes, important mathematical conferences, meetings and so on. The main source of information consists of feedback from the members of the society and users of the website. Anyone can open an account (members have automatic access to the account through which they can also enter their user's profile and pay dues online). After logging in, a registered user can post a news item to the website or add a comment to an item. These posts are moderated by the web team (to prevent possible spam) and are shown on the webpage (usually within 24-48 hours). News appears in reverse chronological order, except for a few prominent items, which are shown at the top.

"Inside EMS" contains the various information compiled for the members of the society, such as the structure of the EMS committees, the agenda of the EMS and so on, providing links allowing access to more detailed information. The webpages of the committees are also accessible via this route so that the reader can easily browse to them. Some are hosted on the main site while others are stored on external sites (like the site of the Committee for Raising Public Awareness). These webpages are maintained by the chair or a designated member of the corresponding committee. The statutes and by-laws of the EMS can also be found here.

Under "Membership", an EMS member (whether individual or corporate) will find methods to pay dues, update personal information and learn about various benefits and discounts.

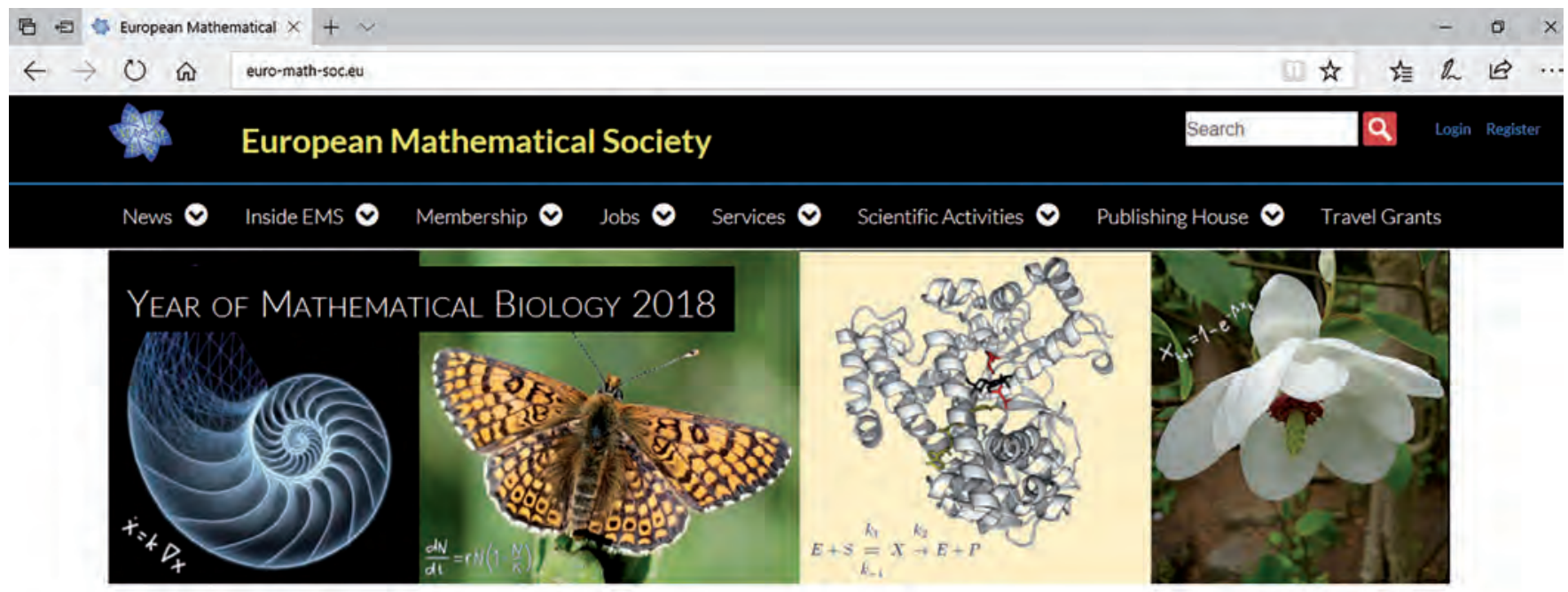

The European Mathematical Society is a learned society representing mathematicians throughout Europe. It promotes the development of all aspects of mathematics in Europe, in particular mathematical research, relations of mathematics to society, relations to European institutions, and mathematical education. The EMS has as its members around 60 national mathematical societies in Europe, 40 mathematical research centres and departments, and

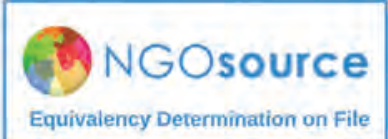
300 individuals 
The label "Jobs" allows a user to browse various job advertisements and positions in mathematics. More than half of the current internet traffic of the EMS goes through this page. Anyone can post a job advertisement (regardless of whether it is a university position or a grant proposal) free of charge unless it is of commercial character. A company advertising a job for mathematicians in the private sector can do the same for a small fee by connecting with the EMS secretary via ems-office@helsinki. fi. Another relevant link is MathHire, a private company based in Europe and offering web based handling of an entire hiring process. MathHire has a cooperation agreement on job advertising with the EMS (with discounts for EMS members).

The label "Services" leads to a collection of many useful items. In particular, "Events" contains announcements of various conferences (including those that are not directly related to the EMS), lecture courses and other mathematical events. The events are shown in calendar form and can be conveniently browsed. There is also an item "Book Reviews" containing reviews on recently published books. These are organised by the team of book reviewers at the Universidad Complutense de Madrid. We want to thank the team, particularly one of the most active reviewers Adhemar Bultheel from Leuven, for their excellent work. We would also like to encourage users who are interested in submitting their own book reviews or in joining the team to contact Vicente Muñoz at vicente.munoz@mat.ucm.es. The "Discussion Forum" item at the bottom is not currently available but we hope to launch it very soon.

The label "Scientific Activities" focuses on scientific events sponsored or organised by the EMS. Members of the EMS will find application forms and information on the rules for submitting them. The next label "Publishing
House" links to the EMS Publishing House, with information on books and journals published by this company. The meaning of the last item "Travel Grants" is clear from its name.

For internal needs, the EMS organised a web team during a recent meeting in Helsinki in February 2017. It has two coordinators Vicente Muñoz (Executive Committee member) and Armen Sergeev (EMS VicePresident) and includes four additional members: Mats Gyllenberg (EMS Treasurer), Elvira Hyvönen (EMS Secretary), Matti Pauna (administrator) and Albert Ruiz (collaborator). This team is responsible for the everyday functioning and maintaining the up-to-date content of the website. We are thinking of inviting a professional external company to make this part of our job more advanced and sophisticated.

We encourage the users of the EMS website both to look for and send to us relevant information on events, news, jobs, book reviews and so on. You may consult EMS Secretary Elvira Hyvönen at ems-office@helsinki.fi.

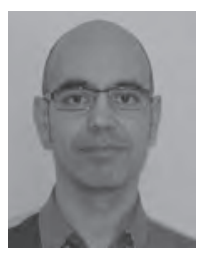

Vicente Muñoz (vicente.munoz@mat.ucm. es) is a member of the EMS Executive Committee and a professor at the Universidad Complutense de Madrid. His research areas are differential geometry and algebraic geometry.

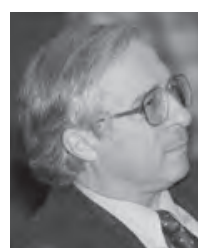

Armen Sergeev (sergeev@mi.ras.ru) is a Vice-President of the EMS and a professor at the Steklov Mathematical Institute in Moscow. His research interests focus on mathematical physics and several complex variables. 